\title{
Clinical Profile of Snake Envenomation with Complications and Outcome in a Tertiary Health Care Centre, Kalburgi
}

\author{
Shoukat A. R. ${ }^{1}$, Muddasir Ahmed Indikar ${ }^{2}$ \\ 1Department of General Medicine, M. R. Medical College, Kalburgi, Karnataka, India. \\ ${ }^{2}$ Department of General Medicine, M. R. Medical College, Kalburgi, Karnataka, India.
}

\section{ABSTRACT}

\section{BACKGROUND}

Bites by snakes represent an important health problem in the tropical world including India. The true incidence of snakebites is difficult to assess and often is under reported. Though the exact number of snake bites is unknown, an estimated 5.4 million people are bitten each year with up to 2.7 million envenoming. Around 81,000 to $1,38,000$ people die each year because of snake bites, and around three times as many amputations and other permanent disabilities are caused by snakebites annually. We wanted to determine frequency of various modes of presentation, complications and management of snakebite.

\section{METHODS}

All patients presenting to emergency department of Basaveshwara Teaching and General Hospital with history of snakebite and features of envenomation were included in the study. All these patients were given Anti-Snake Venom. Symptomatic treatment of complications was done. Semi-structured questionnaire was filled during hospital stay to analyse various characteristics of snakebite and people's attitude towards this problem.

\section{RESULTS}

75 cases of snakebite admitted to Basaveshwara Teaching \& General Hospital, Gulbarga between January 2018 to November 2019 were studied. Males [50 $(62.5 \%)]$ were affected more than females [25 (31.5\%)] in the ratio of 2:1. Most common age group is $20-40$ years [ $45(60 \%)]$. Snakebite is a common health hazard in rural areas [55 (73.34\%)]. Agricultural labourers (68.6\%) are the major sufferers with majority of bites occurring outdoor 60 (80\%). 71 (94.66\%) bites occurred over limbs, out of which 38 (50.66\%) were in lower limbs. Most bites occur between 12 Noon to 12 Midnight 60 patients (81.2\%). Out of 75 patients, 60 (80\%) were poisonous snakebites, $20(20 \%)$ were non-poisonous snakebites. Among $60(80 \%)$ poisonous bites, $32(53.34 \%)$ had neurotoxic manifestations and $28(46.66 \%)$ had hemotoxic manifestations.

\section{CONCLUSIONS}

Snakebite is common in rural setup, in agricultural labourers. Most common victims are males in the age group between 20-40 years. Poisonous bites were more common than non-poisonous snake bites in this study. In neurotoxic envenomation ptosis was the commonest and earliest symptom while in hemotoxic envenomation, most common symptoms were bleeding from bite site and hematuria. The commonest complications were acute renal failure and respiratory paralysis. Shock, infection and gangrene were also noted in some patients. Maximum mortality was observed in patients who were admitted after 24 hours. Early hospitalization and timely ASV administration were the corner stones in the treatment of snakebite.
Corresponding Author: Muddasir Ahmed Indikar, Amina Manzil, Darbar Galli, JM Road, Vijaypur, Karnataka, India.

E-mail: drmuddasir12@gmail.com

DOI: $10.14260 /$ jemds/2020/135

Financial or Other Competing Interests: None.

How to Cite This Article:

Shoukat AR, Indikar MA. Clinical profile of snake envenomation with complications and outcome in a tertiary health care centre, Kalburgi. J. Evolution Med. Dent. Sci. 2020;9(09):608-612, DOI: 10.14260/jemds/2020/135

Submission 20-12-2019,

Peer Review 04-02-2020,

Acceptance 11-02-2020,

Published 02-03-2020.

\section{KEY WORDS}

Snake Bite, Elapidae, Viperidae, Hemotoxic, Neurotoxic, Anti-Snake Venom 


\section{BACKGROUND}

Snakebite is a one of the common medical emergencies encountered in day to-day practice in India. Bites by snakes represent an important health problem in the tropical world including India. The true incidence of snakebites is difficult to assess and often is underreported. Though the exact number of snake bites is unknown, an estimated 5.4 million people are bitten each year with up to 2.7 million envenoming. Around 81000 to 138000 people die each year because of snake bites, and around three times as many amputations and other permanent disabilities are caused by snakebites annually. ${ }^{1}$ There are four medically important venomous land snakes in India, the Indian Krait (Bungarus caeruleus), the common Cobra (Naja naja), the saw scaled viper (Echis carinatus) and Russel's viper (Viper russelli). ${ }^{2}$ The distribution of the snakes differs depending on the particular region and climatic conditions like temperature and rainfall. The pattern of bites also depends on occupation, recreational habits, clothing and season. Most of the snake bites occur in fields, usually during rainy season. Snake bites can be prevented to a certain extent by Awareness and educating the farmers and labourers. ${ }^{2}$ In tropical countries where snake bite is a serious problem there is very little reliable data because of inadequate documentation. There are many causes attributed to high snake bite mortality, lack of adequate training and knowledge of doctors in rational use of ASV is very important. Snake bite is completely treatable if treated in time. Immediate steps should be taken to shift the victim to the hospital as early as possible. Educate the people to avoid traditional heals so that we can reduce the time lapse for the admission of hospital. All cases of doubtful snake bites should be admitted in hospitals to watch the toxicity for proper treatment.

At present very few clinical studies are available on snake envenomation especially on haematological problems of snake envenomation. ${ }^{3}$ Many of the toxins in snake venom interact with clotting mechanism and fibrinolytic system and causes coagulopathy. The occurrence of local and systemic snake bite related symptoms is linked to toxins in snake venom. Snake bite can result in local and systemic complications. Major systemic complications include acute renal failure, neurologic abnormalities requiring ventilator support and disseminated intravascular coagulation. 4,5 Disseminated intravascular coagulation can result in serious life threatening systemic complications like haemorrhage, infarction and even death if the treatment is delayed. 6 Currently, intensive work is being done on the pharmacological, pathological, toxicological and immunological aspects of snake venoms to give a better break to the snake bite victim, which has resulted in production of polyvalent and monovalent anti-snake venoms though the latter is not yet freely available in India. The incidence of snake bite in Gulbarga and its surroundings is high. Hence, this study is undertaken to study the snake bite, clinical presentation with special emphasis on complications and outcome.

We wanted to assess the clinical presentation, complications and outcome of snake bites in North-Eastern region of Karnataka.

\section{METHODS}

This is an observational study conducted among 75 Adult patients admitted with history of snakebite in Basaveshwara Teaching and General Hospital, Gulbarga between January 2018 to December 2019 were studied. The sample size was taken based on the convenience of the study.

\section{Inclusion Criteria}

All patients with history of snakebite and with at least one of the following criteria were included in the study.

1. Patients or attenders have seen the offending snake.

2. Definite fang marks are noted.

3. Features of local or systemic envenomation.

In all the patients presenting with snakebites and fulfilling inclusion criteria, detailed history was taken, and examination done as per proforma. It was determined whether the bites were venomous or non-venomous. Blood was drawn for investigations, bed side tests for bleeding and clotting time was performed and $\mathrm{CBC}$, blood urea, serum creatinine, urine routine, were obtained in all cases. Prothrombin time, LFT, ECG were obtained when indicated. All the patients in whom it was decided to give ASV were pre medicated with chlorpheniramine maleate. Intracutaneous testing was carried out. All patients who showed any reaction were given further dose of chlorpheniramine, hydrocortisone and started on ASV infusion. Initial dosage was 2-5 vials for mild, 5-9 vials for moderate and 10-15 vials for severe envenomation for first 8-10 hours. Further dosage was based on clinical judgment and preference of treating physician.

Neostigmine was administered to all patients with neuroparalysis till reversal of Neurotoxic manifestations. Blood transfusion, respiratory assistance and dialysis was carried out as and when indicated. All the cases were administered injection tetanus toxoid and appropriate antibiotics and anti-inflammatory drugs were required. Patients developing severe cellulitis were referred to surgeons for necessary treatment like multiple incisions and skin grafting. The patients initially monitored continuously and later once daily and at time of discharge. Notes were made regarding appearance and disappearance of signs, symptoms and complications and treatment received. The study was approved by Ethical Committee and informed consent was obtained.

\section{Statistical analysis}

The results were analyzed by using The Statistical Package for Social Science SSPSS Version 20 will be used for Data Analysis. Mean, median, and SD are used to describe quantitative data. Qualitative data are summarized using frequency and percentage.

\section{RESULTS}

During the study period from January 2018 to December 2019.75 patients were included in the study as per the inclusion criteria. Following are the observations made in those 75 patients. 


\begin{tabular}{|c|c|c|}
\hline \multicolumn{3}{|c|}{ Age Wise Distribution of Snake Bite Cases } \\
\hline Age (Years) & No. of cases & Percentage \\
\hline $13-19$ & 15 & 20.00 \\
\hline $20-29$ & 30 & 40.00 \\
\hline $30-39$ & 15 & 20.00 \\
\hline $40-49$ & 10 & 13.33 \\
\hline$>50$ years & 5 & 6.67 \\
\hline Total & $\mathbf{7 5}$ & $\mathbf{1 0 0 . 0 0}$ \\
\hline \multicolumn{3}{|c|}{ Sex-Wise Distribution of Snake Bite Cases } \\
\hline Sex & No. of cases & Percentage \\
\hline Males & 50 & 66.66 \\
\hline Females & 25 & 33.34 \\
\hline Total & $\mathbf{7 5}$ & $\mathbf{1 0 0 . 0 0}$ \\
\hline \multicolumn{2}{|c|}{ Table 1. Age and Sex Wise Distribution of Cases } \\
\hline
\end{tabular}

The snakebites were observed in all age groups. The youngest patient was 15 years old and oldest was 69 years. The majority of patients $(80 \%)$ were below 40 years of age. The snakebite is more common in males. The male to female ratio is approximately $2: 1$.

\begin{tabular}{|c|c|c|}
\hline \multicolumn{3}{|c|}{ Distribution of Cases According to Areas } \\
\hline Place & No. of cases & Percentage \\
\hline Urban & 20 & 26.66 \\
\hline Rural & 55 & 73.34 \\
\hline Total & 75 & 100.00 \\
\hline Place & Nistribution of Cases According to Activities \\
\hline Outdoor & 60 & Percentage \\
\hline Indoor & 15 & 80.00 \\
\hline Total & 75 & 20.00 \\
\hline \multicolumn{2}{|c|}{ Distribution of Cases According to Sites of Bite } \\
\hline Sites of the Bite & No. of Cases & Percentage \\
\hline Lower limb & 38 & 50.66 \\
\hline Upper limb & 33 & 44.00 \\
\hline Other parts & 4 & 5.34 \\
\hline Total & 75 & 100.00 \\
\hline \multicolumn{2}{|c|}{ Table 2. Distribution of Cases According to } \\
\hline
\end{tabular}

Snakebite is mainly seen in rural agricultural labours as $55(73.34 \%)$ of our cases were from rural places, while the rest $20(26.66 \%)$ were from urban places. The bites occurred predominantly during outdoor activities Limbs 71 (94.66\%) are the commonest site for bite. Among the limbs lower limbs were commonest site 38 (50.66\%), followed closely by upper limb bite 33 (44.0\%).Four patients had unusual sites of bite, three on face and one over right scapula, all four bites occurred while patients were asleep.

\begin{tabular}{|c|c|c|}
\hline \multicolumn{3}{|c|}{ Types of Snake Bites } \\
\hline Type of Snake Bites & No. of Cases & Percentage \\
\hline Non- poisonous & 15 & 20.00 \\
\hline Poisonous & 60 & 80.00 \\
\hline Elapidae & 30 & 40.00 \\
\hline Viperidae & 24 & 32.00 \\
\hline Unidentified Types of Envenomation \\
\hline Type of Envenomation & No. of Cases (n=60) & Percentage \\
\hline Haemorrhagic & 28 & 46.66 \\
\hline Neurotoxic & 32 & 53.34 \\
\hline Cardiotoxic & -- & -- \\
\hline Total & 60 & 100.00 \\
\hline Table 3. Distribution of Cases According to Types of Snake \\
\hline \multicolumn{2}{|c|}{ Bites and Envenomation } \\
\hline
\end{tabular}

Among all snakebites, majority of cases were due to poisonous snakebites 60 patients $(80 \%)$. Among them 30 patients (40\%) had been bitten with Elapidae snakes while Viperidae snakes had bitten 32\% (24 patients). In $8 \%$ of patients the biting snake could not be identified. The incidence of venomous snakebites was 60 (80\%), whereas non-poisonous constituted only $20 \%$. Among poisonous bites neurotoxic manifestations 32 (53.34\%) were more common than haemorrhagic manifestations 28 (46.66\%).

\begin{tabular}{|c|c|c|}
\hline \multicolumn{3}{|c|}{ Symptoms Wise Distribution of Cases } \\
\hline Symptoms & No. of Cases & Percentage \\
\hline Fright and anxiety & 60 & 80.00 \\
\hline Vomiting & 20 & 26.66 \\
\hline Pain abdomen & 6 & 8.00 \\
\hline Local pain & 34 & 45.33 \\
\hline Numbness & 08 & 10.66 \\
\hline Local swelling & 26 & 34.66 \\
\hline Bleeding from wound & 11 & 14.66 \\
\hline Hematuria & 10 & 13.33 \\
\hline Ecchymosis & 06 & 8.00 \\
\hline Complications Wise Distribution of Cases \\
\hline Complication & No. of Patients & Percentage \\
\hline Acute renal failure & 15 & 20.00 \\
\hline Respiratory paralysis & 10 & 13.33 \\
\hline Shock & 3 & 4.00 \\
\hline Limb loss & 0 & 0.00 \\
\hline Infection & 1 & 1.33 \\
\hline Gangrene & 1 & 1.33 \\
\hline Total & 30 & 40.00 \\
\hline
\end{tabular}

Table 4. Symptoms and Complications Wise Distribution of Cases

Fright was a prominent symptom seen in 60 (80\%) of patients. It was found both in poisonous and non-poisonous bites usually developed within minutes of bite. Most common complication was acute renal failure was noted in 15 (20\%) of patients. All of them were viper bites.

\begin{tabular}{|c|c|c|}
\hline Manifestation & No. of Cases & Percentage \\
\hline Ptosis & 32 & 100.00 \\
\hline Ophthalmoplegia & 24 & 75.00 \\
\hline Palatal and pharyngeal palsy & 22 & 68.75 \\
\hline Respiratory palsy & 12 & 37.50 \\
\hline Limb paralysis & 2 & 6.25 \\
\hline Convulsions & 0 & 0.00 \\
\hline Coma & 1 & 3.125 \\
\hline Table 5. Presentation of Neurotoxic Venom Poisoning \\
\hline
\end{tabular}

All the 32 patients developed ptosis (100\%). followed by ophthalmoplegia 24 in patients $(75 \%)$

\section{DISCUSSION}

Snakebite is one of the major medical emergency and hazard to life and health of people in the predominantly agricultural country like ours.

\section{Age Incidence}

In our study snakebite was observed in all age groups. The maximum number patients were in the age group 10-39 years, they constituted $80 \%$ patients, which is comparable to that of Sawai et $\mathrm{al}^{7}(70.28 \%)$ and Nigam et $\mathrm{al}^{8} 83.3 \%$. Biyajenee Mohapatra et al also concluded that snakebite and deaths peaked at ages 15-29 years. Maximum number of cases were seen in 10 to 39 years age group. This is because, people belonging to this age group are prone for snake bite because of occupational activities.

\section{Sex Incidence}

The incidence of snakebite is more common among males shown in our study as well as others. It is obviously due to the increased risk of exposure to the snake bite occupationally.

\section{Population Incidence}

Snakebite is mainly the disease of the rural population. In the present study 55 (73.34\%) patients were from rural 
population and $90(26.66 \%)$ from urban population. The findings are consistent with finding of Bhat ${ }^{9}$ and Kulkarni. ${ }^{10}$

\section{Outdoor / Indoor}

An incidence of 60 (80\%) of snakebite was reported during outdoor activities in the present study. A similar high incidence was also reported by Banerjee. ${ }^{11}$

\section{Site of Bite}

In our study, maximum number of bites occurred on lower extremities 38 (50.66\%). The lower and upper extremities constituted more than 71 (94.66\%), bite sites suggesting the site of the bite was predominantly determined by accidental or inadvertent contact of the snake during the activities. The incidence in our study is similar as observed by Sawai et al ${ }^{12}$ (97.90\%) and Hati et al. ${ }^{13}$

\section{Types of Envenomation}

The neurotoxicity 32 (53.34\%) was found more frequently than haemorrhagic type 28 (46.66\%). In contrast Nigam et al, Sarangi et al,14 Bawaskal et al and Emam SJ et al reported a high incidence of haemorrhagic manifestations. No cardiotoxicity was noted in our study. It is due to the fact that relative prevalence of toxic varieties of snakes could vary in different region of country depending on prevalence and distribution of snakes.

\section{Haematotoxic Manifestations}

In the present study, bleeding from bite site was most common $(71.42 \%)$, followed by hematuria (35.71\%), gum bleeding (25\%) and ecchymosis (25\%). Sarangi 15 et al reported bleeding from bite site in only (44.4\%), followed by hematemesis (39\%), ecchymosis $(27.7 \%)$ and gum bleeding $(27.7 \%)$. Contrary to above studies, Saini reported hematuria was most common presentation (83.3\%) followed by bleeding from bite site (50\%), bleeding gum (41.6\%), and Hematemesis (33.3\%). ${ }^{16}$

\section{Complications}

Most common complications were acute renal failure was noted in $15(20 \%)$ of patients. All of them were viper bites. Among them 4 (26.66\%) patients required hemodialysis, while remaining patients recovered totally on conservative treatment. Though respiratory inadequacy was noted in 10 patients $(13.3 \%)$, only $4(5.2 \%)$ had respiratory paralysis requiring assisted ventilation. Three patients were put on ventilation, while one was managed with Ambu-bag ventilation. Though shock was observed in three (4\%) cases, it was mainly attributable to blood loss rather than cardiotoxicity.

\section{CONCLUSIONS}

Snake bite though preventable in principle, remains to be one of the common medical emergencies being more frequent in rural agricultural and farm workers. Most common age group is 20-40 years. Adult males are more prone to the bites. Poisonous bites are more common than non-poisonous bites in hospitalized patients. In neurotoxic envenomation, ptosis was the commonest and earliest symptom while in hemotoxic envenomation, most common symptoms were bleeding from bite site and hematuria. More Elapidae bites are seen in this area than viper bites. The commonest complications were acute renal failure and respiratory paralysis. Shock, infection and gangrene were also noted in some patients. Maximum mortality was observed in patients who were admitted after 24 hours. Early hospitalization and timely ASV was the corner stone in the treatment of snakebite. Still majority of the patients do not seek medical attention immediately. Most of them visit traditional healers. Thus, there is a need for giving health education regarding the snakebites, their toxic effects, effectiveness of hospitalization, ASV therapy in bites and prevention of snakebite by appropriate measures. This will definitely reduce the incidence and complications of snakebites.

\section{REFERENCES}

[1] World health organization report [www.who.int/newsroom/fact-sheets/detail/snakebite-envenoming] $8^{\text {th }}$ April 2019.

[2] Lívia SR, Glória EMF, Carla CP, et al. Acute kidney injury caused by Bothrops snake venom. Nephron Clin Pract 2011;119(2):c131-7.

[3] Kumar KPG. Haematotoxic snake envenomation prothrombin time is a better predictor of mortality. Amrita J Medicine 2011;7(2):41-44.

[4] Lee JA, Kim SY, Hyun SC, et al. Clinical features in snake bite. J Korean Soc Emerg Med 1996;7:580-9.

[5] Han BG, Choi SO, Kim HY, et al. A study of the complication of poisonous snake bite. Korean J Intern Med 1996;50:399-404.

[6] Hasiba U, Rosenbach LM, Rockwell D, et al. Dic-like syndrome after envenomation by the snake, Crotalus horridus horridus. N Engl J Med 1975;292(10):505-7.

[7] Sawai Y, Honma M. Snake bites in India. Snake 1975;7:116.

[8] Nigam P, Tandon VK, Rajendra Kumar, et al. Snake bite. A clinical study. The Indian Journal of Medical Sciences 1973;27:697-704.

[9] Bhat RN. Viperine snake bite poisoning in Jammu. J of Indian Med Assoc 1975;63(12):383-92.

[10] Kulkarni ML, Anees S. Snake venom poisoning: experience with 633 cases. Indian Pediatrics 1981;18:193-7.

[11] Banerjee RN. Poisonous snakes in India, their venoms, symptomatology and treatment of envenomation. In: Ahuja MMS, edr. Progress in clinical medicine in India. $1^{\text {st }}$ edn. New Delhi: Arnold Heinman Publishers 1978;13677.

[12] Thompson CJS. Poisons and poisoners. London: Harold Shaylor 1931.

[13] Hati AK, Mandal M, De MK, et al. Epidemiology of snake bite in the district of Burdwan, West Bengal. J Ind Med Assoc 1992;90(6):145-7.

[14] Lallo DG, Trevett AJ, Saweri A, et al. The epidemiology of snake bite in central province and National Capital district, Papua New Guinea. Transactions of the royal society of tropical medicine and hygiene 1995;89(2):178-82. 
[15] Sarangi A, Jenal L, Sahoo H. A profile of snake bite poisoning with special reference to hematological, renal, rernological and electrocardiographic abnormalities. JAPI 1977: p. 555-60.
[16] Saini RK. Haematologic alteration in snake bite poisoning. Indian J Med Res 1985;82:77-82. 